\title{
A comparative analysis of the cycle fecundity rates associated with ovarian hyperstimulation along with IUI versus medical management in the treatment of mild to moderate oligozoospermia in males
}

\author{
Tanaya Acharyya*, Arun Paul Choudhury
}

Department of Obstetrics and Gynecology, Silchar Medical College and Hospital, Silchar, Assam, India

Received: 20 December 2020

Accepted: 18 January 2021

*Correspondence:

Dr. Tanaya Acharyya,

E-mail: Tanayaacharyya.tiarra@gmail.com

Copyright: () the author(s), publisher and licensee Medip Academy. This is an open-access article distributed under the terms of the Creative Commons Attribution Non-Commercial License, which permits unrestricted non-commercial use, distribution, and reproduction in any medium, provided the original work is properly cited.

\section{ABSTRACT}

Background: To compare the pregnancy rate in infertile couples with mild to moderate oligozoospermia receiving ovarian hyperstimulation and IUI, with that of medical management with CC.

Methods: A total 120 couples with males having sperm concentration between 5 to $20 \mathrm{million} / \mathrm{ml}$, normal serum gonadotropins and testosterone, and a presumptively fertile partner were enrolled in this prospective clinical study, during the study period of 19 months, $31^{\text {st }}$ January 2019 till $1^{\text {st }}$ September 2020. 120 couples were divided randomly into two groups A $(n=60)$ and B $(n=60)$. In group A, 60 couples were subdivided equally into 3 groups, each having 20 couples. Ovarian hyperstimulation protocols with IUI were used in different subgroups in group A. A total of 216 IUI cycles done for 60 couples. While in group B, 60 males with oligozoospermia were prescribed CC treatment $25 \mathrm{mg} /$ day on alternate days for 3 months.

Results: Out of 60 patients in group A, 24 achieved pregnancy with a cycle fecundity rate of $4 \%$ in CC+IUI, $9.87 \%$ in HMG+CC+IUI and $21.67 \%$ in HMG+IUI. 5 out of 60 patients in group B achieved pregnancy with cycle fecundity rate of $2.78 \%$.

Conclusions: These data suggest that acceptable pregnancy rates can be achieved with IUI combined with ovarian hyperstimulation in males with oligozoospermia. The role of $\mathrm{CC}$ treatment in males with oligozoospermia in improving the pregnancy outcome is extremely mearge. Thus, owing to the cost effectiveness and non-invasive modality, IUI is preferred prior to other more invasive and potentially costly reproductive technologies in the treatment of male factor subfertility.

Keywords: Cycle fecundity rate, Intrauterine insemination, Ovarian hyperstimulation, Male factor subfertility, Semen analysis

\section{INTRODUCTION}

Parenthood is a joyful, challenging and enriching experience and most of us take it for granted. But for couples coping with infertility, building a family can feel like an insurmountable hurdle. In the developing countries, the word infertility is highly stigmatizing and leads to profound social consequences for infertile couples. Infertility is defined as failure to conceive after 12 months of unprotected intercourse. It affects one in seven couples. After one year of unprotected intercourse,
$85 \%$ to $90 \%$ of couples will successfully conceive. Among the remaining couples, half of them will conceive during the second year. The National Institute for Health and Care excellence (NICE) and the American Society for Reproductive Medicine (ASRM) recommend starting infertility investigations after 12 months of unprotected intercourse. $^{1}$ This takes into account that natural conception may occur during the period of investigation. Earlier investigation is recommended after 6 months of trying to conceive in women over the age of 35 years due to age related decline in fertility as well as diminishing 
assisted reproductive technology (ART) outcomes in this age category. Earlier assessment may also be justified when an infertility factor is known or when it is highly suspected in the female (such as oligo/amenorrhea, tubal or uterine disease, or endometriosis) or in males (such as undescended testes).

The etiologies of infertility are: ovulatory disorders $25 \%$, tubal damage $20 \%$, male factors causing infertility $30 \%$, and uterine or peritoneal disorders $10 \%$.

The common cause of male infertility are obstruction of genital tract, testicular failure, varicocoele and genetic and ejaculatory disorders. About $25 \%$ of cases of infertility remain unexplained. ${ }^{2}$ Both members of the couple need to be evaluated. In about $40 \%$ of cases disorders are found in both males and females.

First step in the treatment cascade in couples with unexplained subfertility, cervical factor subfertility and male subfertility is intrauterine insemination (IUI). IUI is easy to perform, inexpensive and provides less burden to the couples. For these reasons, it is probably the most frequently performed treatment in daily fertility practice. The quintessence of IUI is based on three steps. First, semen processing based on the theory that by this process, the number of motile sperm is increased at the site of fertilisation. Second, bypassing the possibly hostile cervical mucus and bringing the semen in closer proximity of the oocyte. Third, optimising the timing by monitoring or inducing ovulation. All these steps, should theoretically increase the probability of conception, especially in case of compromised semen parameters and cervical hostility. ${ }^{3}$

IUI can be performed with or without ovarian hyperstimulation. The aim of ovarian hyperstimulation is to correct subtle cycle disorders, to increase the number of oocytes available for fertilisation and to improve the timing of insemination. The monthly fecundity rate can be improved with superovulation and IUI.

The present study was a prospective clinical study, conducted to evaluate the prognostic and clinical value of male oligozoospermia obtained during fertility work up amongst the couples undergoing IUI accompanied with ovulation induction for male factor subfertility, and to compare it with the efficacy of medical management to improve the fertility outcome in oligozoospermic males.

\section{METHODS}

All patients attending gynaecology OPD, Silchar Medical College and Hospital, Assam for treatment of infertility during the time period from $31^{\text {st }}$ January, 2019 till $1^{\text {st }}$ September, 2020, underwent a complete infertility workup that included profound medical history, semen analysis, mid luteal serum progesterone, prolactin, thyroid hormones, tubal assessment (by laparoscopy or hysterosalpingography) and TVS.

\section{Inclusion criteria}

We included only those infertile couples with male factor etiology in whom two or more semen analyses obtained 1 month apart shows a sperm count $>5$ to $<20$ million $/ \mathrm{ml}$.

\section{Inclusion criteria}

Couples with ovulatory dysfunction, tubal factors and other female factor etiology as well as unexplained infertility were excluded from the study.

The IUI procedure was conducted in the Andrology Laboratory, Department of Obstetrics and Gynaecology, Silchar Medical College and Hospital.

This study was conducted in accordance with the guidelines described in the ethical committee meeting, held at Silchar Medical College and Hospital, Assam on $10^{\text {th }}$ January, 2019. Informed consent was obtained in all cases.

A total of 60 couples with male oligozoospermia had been treated with IUI combined with ovarian hyperstimulation with $\mathrm{HMG}, \mathrm{HMG}+\mathrm{CC}$ and $\mathrm{CC}$ in group A. Each hyperstimulation prolocol included 20 patients, who were randomly distributed into three groups. Cycle fecundity rates were examined in three therapeutic groups.

\section{Semen preparation technique}

An ejaculatory absteinance interval 3 to 7 days was taken. Sexual intercourse was prohibited 2 days before injection HCG in stimulated cycles. Swim up technique was used to process semen samples for IUI. Semen samples were taken in sterile dry glass container and transferred into a centrifuge tube. Double quantity of cryo HTF medium was added into the sample, mixed well and centrifuged at 1200-1500 RPM for 10 minutes. Following centrifugation, the supernatant was removed. 1.5 to $2 \mathrm{ml}$ of cryo-HTF medium was carefully layered over this pellet. The tube was kept inclined in the incubator for 4560 minutes. The supernatant was then aspirated and transferred to the second tube. The tube was then centrifuged at 1000-1200 rpm for 4-5 minutes, the supernatant removed and the pellet resuspended in $0.5 \mathrm{ml}$ of cryo-HTF medium. The final sample for IUI thus prepared. Post wash examination was done on a small aliquot and yield was calculated.

Three different protocols were used for ovarian stimulation: a) Clomiphene citrate (CC) $100 \mathrm{mg}$ on day 2 to day 6 of the cycle, the patients were monitored with TVS for the follicular response. Injection hCG (human chorionic gonadotropin) was administered 7 days following last dose of $\mathrm{CC}$. b) Clomiphene citrate (CC) and human menopausal gonadotropin (HMG) cycles: This protocol consists of CC $100 \mathrm{mg}$ from day 2 to day 6 of the cycle and 75 IU HMG on day 6 to 9 of the cycle. c) 
Gonadotropin injection HMG 150IU given for 3 cycles from day 3 and dosage titrated to $75 \mathrm{IU}$ according to follicular response by serial TVS.

The ovarian response was monitored with serial TVS starting from day 7 of the cycle, for measurement of number and diameter of the follicles, along with assessment of thickness and morphology of the endometrium. The ovulation trigger with Injection hCG $10,000 \mathrm{IU}$ was administered intramuscular on appropriate day considering follicular size $(18-20 \mathrm{~mm})$. IUI was performed within 12 to 36 hours after hCG injection. The patient remained supine for $30 \mathrm{mins}$ thereafter. Injection progesterone $50 \mathrm{mg} /$ day i.m., given to all patients for luteal phase support. In this study 3 or 6 cycles of IUI was done, with 1 insemination in one cycle.

In group B, 60 males with oligozoospermia were given tab CC $25 \mathrm{mg}$ on every alternate days for 3 months. The changes in sperm quality was assessed after the treatment and its outcome in relation to cycle fecundity rate was calculated.

Urine $\beta$ hCG test was done in all cases after 7 days of missed period or 21 days of IUI to determine clinical pregnancy. Positive pregnancy test was confirmed by USG 2 weeks later. A comparative analysis between group A and group B in relation to cycle fecundity rates was done.

\section{Statistical analysis}

Data was presented as arithmetic mean \pm standard deviation (SD) and range. Sperm quality before and after sperm preparation was compared by paired student $t$ test in group A. Paired student $t$ test was also used to compare sperm quality before and after CC treatment in group B. The results were analysed by comparing the pregnancy rates between group A and group B by Chi-square test. Statistical significance was considered as $\mathrm{p}<0.05$.

Fecundity (f) was calculated according to Cramer et al. ${ }^{4}$

Formula for monthly fecundity $(\mathrm{f})=$ Number of pregnancies per (divided by) total number of cycles.

Here, number of cycles per patient is 3 or 6 .

\section{RESULTS}

During the time period of $31^{\text {st }}$ January, 2019 to $1^{\text {st }}$ September, 2020, 120 couples with mild to moderate oligozoospermia ( $>5$ to $<20 \mathrm{million} / \mathrm{ml}$ ) were taken into this study and were divided randomly into two groups A and B consisting of 60 cases in each group. In group A, IUI was done along with ovulation induction by $\mathrm{CC}$, $\mathrm{CC}+\mathrm{HMG}$ and HMG. A total of 216 cycles of insemination was done in group A. In group B, males with oligozoospermia were given medical treatment with $\mathrm{CC}$ to improve sperm count. The treatment outcome, i.e. pregnancy rate or the cycle fecundity rate was compared between the two groups.

It has been seen that, in group $\mathrm{A}$, the mean sperm count in prewash naive semen sample was $11.723 \pm 2.69$ million $/ \mathrm{ml}$ and that in post-wash semen sample after sperm preparation was $10.208 \pm 2.85 \mathrm{million} / \mathrm{ml}$. Thus, following sperm preparation by swim up technique, the mean inseminating motile sperm count in post-wash sample was significantly reduced as compared to the naive semen sample, with a $\mathrm{p}$ value of $<0.05$. However, the mean sperm motility in post-wash sample was $45.70 \pm 7.53 \%$, which is significantly higher as compared to the mean motility in prewash sample $41.43 \pm 7.76 \%$, with a $\mathrm{p}$ value of $<0.05$.

In group $\mathrm{B}$, the mean pretreatment sperm concentration was $10.67 \pm 1.89 \mathrm{million} / \mathrm{ml}$, whereas following CC treatment mean sperm concentration increased to $16.33 \pm 1.75 \mathrm{million} / \mathrm{ml}$. Thus, there was significant improvement of sperm concentration following CC treatment, with a $\mathrm{p}$ value of $<0.05$. On the other hand, mean pre-treatment sperm motility was $44.38 \pm 9.02 \%$ and post treatment sperm motility was $44.95 \pm 9.03 \%$. Thus, there was no significant improvement in sperm motility following CC treatment with a p value of $>0.05$.

Table 1: Mean and standard deviation of sperm concentration and sperm motility in pre-wash and postwash semen sample in group $A$ and pre-treatment and post-treatment semen sample in group B.

\begin{tabular}{|c|c|c|c|c|}
\hline & & Mean & SD & $\begin{array}{l}\mathbf{p} \\
\text { value }\end{array}$ \\
\hline \multirow[t]{2}{*}{$\begin{array}{l}\text { Group } \\
\text { A }\end{array}$} & $\begin{array}{l}\text { Sperm count (in } \\
\text { million/ml) in naive } \\
\text { semen sample (pre- } \\
\text { wash) }\end{array}$ & 11.723 & 2.69 & \\
\hline & $\begin{array}{l}\text { Post-wash sperm } \\
\text { count (in million/ml) }\end{array}$ & 10.208 & 2.85 & $<0.05$ \\
\hline \multirow[t]{2}{*}{$\begin{array}{l}\text { Group } \\
\text { A }\end{array}$} & $\begin{array}{l}\text { Sperm motility (in } \\
\% \text { ) in naive semen } \\
\text { sample (pre-wash) }\end{array}$ & 41.433 & 7.76 & \\
\hline & $\begin{array}{l}\text { Post-wash sperm } \\
\text { motility (in \%) }\end{array}$ & 45.700 & 7.53 & $<0.05$ \\
\hline \multirow[t]{2}{*}{$\begin{array}{l}\text { Group } \\
\text { B }\end{array}$} & $\begin{array}{l}\text { Sperm count (in } \\
\text { million/ml) in pre- } \\
\text { treatment semen } \\
\text { sample }\end{array}$ & 10.667 & 1.89 & \\
\hline & $\begin{array}{l}\text { Post-treatment sperm } \\
\text { count (in million/ml) }\end{array}$ & 16.333 & 1.75 & $<0.05$ \\
\hline \multirow[t]{2}{*}{$\begin{array}{l}\text { Group } \\
\text { B }\end{array}$} & $\begin{array}{l}\text { Sperm motility (in } \\
\% \text { ) in pre-treatment } \\
\text { semen sample }\end{array}$ & 44.383 & 9.02 & \\
\hline & $\begin{array}{l}\text { Post-treatment sperm } \\
\text { motility (in \%) }\end{array}$ & 44.950 & 9.03 & $>0.05$ \\
\hline
\end{tabular}

In this study, 60 patients in group A were divided into three groups randomly in whom various types of 
ovulation hyperstimulation protocol was being administered. 20 patients were included in each group. The drugs that were used in ovulation induction protocols are $\mathrm{CC}, \mathrm{CC}+\mathrm{HMG}$ and HMG. A total of 3 or 6 cycles of IUI were done in each patient. Ovulation induction was given in every cycle of IUI; thus a total of 75 cycles for CC+IUI, 81 cycles for CC+HMG+IUI and 60 cycles for HMG+IUI. The resulting number of pregnancies were 3 in $\mathrm{CC}+\mathrm{IUI}$ group, 8 in $\mathrm{CC}+\mathrm{HMG}+\mathrm{IUI}$ group and 13 in HMG+IUI group. The cycle fecundity rate as calculated according to Cramer et al (1979) were 4\%, 9.87\% and $21.67 \%$ in $\mathrm{CC}+\mathrm{IUI}, \mathrm{CC}+\mathrm{HMG}+\mathrm{IUI}$ and $\mathrm{HMG}+\mathrm{IUI}$ respectively.

On the other hand, 60 oligozoospermia patients in group $\mathrm{B}$ were given $\mathrm{CC}$ for 3 cycles or months to improve the sperm count. There were 5 number of total pregnancies in this group. The outcome as estimated by the cycle fecundity rate or the pregnancy rate per cycle was $2.78 \%$.

On comparing the cycle fecundity rates in both the groups $\mathrm{A}$ and $\mathrm{B}$, it was seen that the fecundity rate was significantly higher in group A than that of group B, with $\mathrm{p}$ value $<0.0004$.

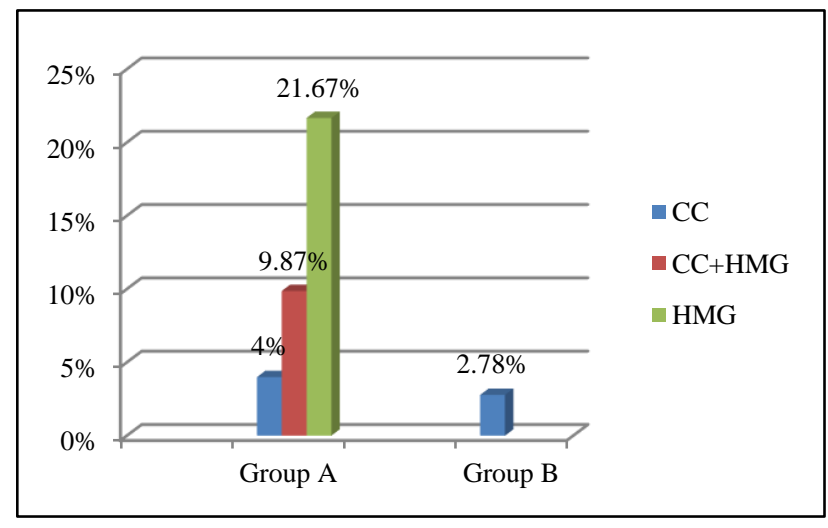

Figure 1: Comparison of cycle fecundity rates between two groups $A$ and $B$.

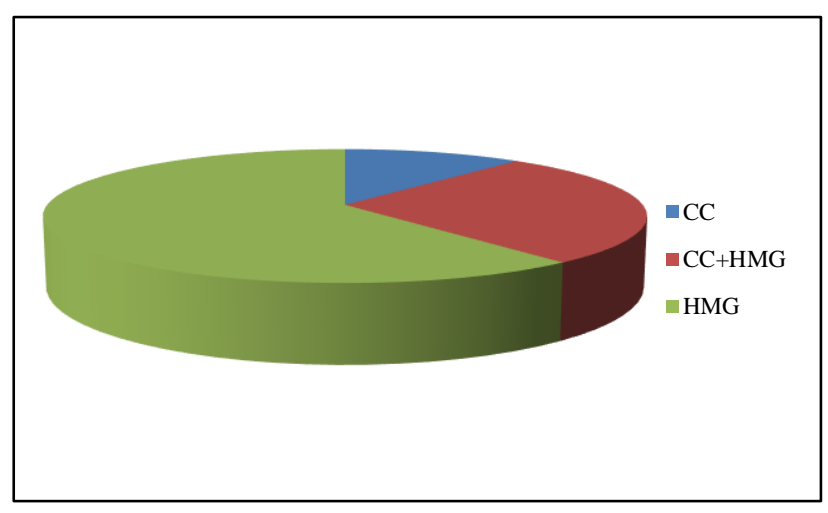

Figure 2: Comparison of cycle fecundity rates among various ovulation induction protocols in group $A$.

Also it was seen that in group A, among the different ovulation induction protocols, HMG+IUI had significantly greater cycle fecundity rate $(21.67 \%)$ as compared to CC+HMG+IUI $(9.87 \%)$ and CC+IUI (4\%), with a $\mathrm{p}$ value of $0.044(<0.05)$.

\section{DISCUSSION}

Intrauterine insemination has been used for treatment of several infertility related problems, including idiopathic infertility, cervical factor infertility, male factor infertility, endometriosis and combination of these factors. IUI and direct transfer of sperm in the uterine cavity is one of the major advances in the treatment of infertility. The success of this procedure in achieving pregnancy is varied in range from 3.4 to $62 \%$, with a mean of $28 \%$. The wide range of success is due to results of various factors of infertility reported in a collective way and the various techniques used in the semen preparation technique. In male subfertility, maximum pregnancy rate is achieved when ovarian stimulation is combined with IUI. The effects of different protocols of ovulation induction in IUI cycles on infertile couples with male subfertility varies widely and is discussed in this present study. Also it is seen that conservative treatment of male oligozoospermia with $\mathrm{CC}$ has a very little significance in improving the pregnancy outcome.

In the present study, in group $\mathrm{A}$, the quality of spermatozoa in terms of sperm concentration and motility after sperm washing technique changed significantly as compared to naive semen sample. The sperm count decreased significantly in post-wash sample as compared to pre wash, $\mathrm{p}$ value $<0.05$. Whereas, significant increase in sperm motility has been noted in post-wash sample as compared to pre wash, $\mathrm{p}$ value $<0.05$. A study by Aribarg et al on IUI of washed spermatozoa for treatment of oligozoospermia, also found that there was significant difference in semen quality in terms of sperm concentration and motility before and after sperm preparation, with a $\mathrm{p}$ value $<0.05$. Aribarg et al showed that the sperm motility increased significantly after sperm preparation but sperm count decreased. ${ }^{5}$

In group $B$, the quality of spermatozoa in terms of sperm concentration improved significantly after CC treatment ( $p$ value $<0.05$ ) whereas, sperm motility did not have any significant change ( $p$ value $>0.05$ ). It has been seen that sperm count increased significantly after 3 months of treatment with CC. Similar results in terms of sperm count and motility was found by Homonnai et al. ${ }^{6}$

The usefulness of IUI as a treatment for oligozoospermia remains somewhat controversial because some groups have reported that IUI is quite effective in males with oligozoospermia (Kerin et al, Cruz et al, Horing et al, Horvath et al, Martinez et al) whereas others have found it to be ineffective (Confino et al). ${ }^{7-12}$

In this study we assessed the effectiveness of IUI using motile spermatozoa in the treatment of couples with oligozoospermia in comparison with the medical 
management of oligozoospermia with CC. In addition, ovulation induction by controlled ovarian hyperstimulation was used in group A.

Controlled ovarian hyperstimulation with IUI has gained widespread acceptance as treatment for variety of infertility related diagnosis. The theory behind use of controlled ovarian hyperstimulation is that by increasing the number of oocytes per cycle and increasing the number of sperms present in uterine cavity (by IUI) per oocyte, the cycle fecundity should be increased (Dodson et al). ${ }^{13}$ Different hormonal treatment protocols have been used for controlled ovarian hyperstimulation, including $\mathrm{CC}, \mathrm{CC}+\mathrm{HMG}$ or $\mathrm{HMG}$ alone. The reported cycle fecundity rates vary greatly among the various stimulation protocols used in IUI for males with oligozoospermia. Those reported are $3 \%$ to $12 \%$ for $\mathrm{CC}$, $2.5 \%$ to $22 \%$ for $\mathrm{CC}+\mathrm{HMG}$ and $7 \%$ to $30 \%$ for $\mathrm{HMG}$.

In this study, IUI for treatment of oligozoospermia during stimulated cycles resulted in a significantly improved pregnancy rate compared to medical management of oligozoospermia with $\mathrm{CC}$ alone with a $\mathrm{p}$ value of $<0.05$.

The pregnancy rates per cycle in group A were $4 \%$ for $\mathrm{CC}+\mathrm{IUI}, 9.87 \%$ for $\mathrm{CC}+\mathrm{HMG}+\mathrm{IUI}$ and $21.67 \%$ for HMG+IUI. The maximum pregnancy rate was for HMG+IUI group. In a study by Rashidi et al it was found that the fecundity rates were $6.52 \%$ in $\mathrm{CC}+\mathrm{IUI}$ group and $12.12 \%$ in $\mathrm{CC}+\mathrm{HMG}+\mathrm{IUI}$ group. ${ }^{14}$ Fecundity rate as reported by Manganiello et al was $4.1 \%$ with $\mathrm{CC}+\mathrm{IUI} .^{15}$ In a study conducted by Mahani et al the fecundity rate with $\mathrm{CC}$ and IUI was $4 \%, \mathrm{CC}+\mathrm{HMG}+\mathrm{IUI}$ was $7 \%$ and HMG+IUI was $9 \% .{ }^{16} \mathrm{~A}$ study conducted by Chaffkin et al in male oligozoospermia, demonstrated a cycle fecundity of $15.3 \%$ when IUI cycles are stimulated with HMG. ${ }^{17}$

In group $\mathrm{B}$ the pregnancy rate per cycle with CC treatment of husband with oligozoospermia is $2.78 \%$. In a study by Sokol et al, on a controlled comparison of the efficacy of clomiphene citrate in male infertility, pregnancy rates per cycle was $9.09 \% .{ }^{18} \mathrm{CC}$ is a wellknown drug in fertility clinics that is used to increase gonadotropin secretion. In this study it was found that there is significant improvement in sperm count after three months of CC therapy in males with oligozoospermia. In addition, $\mathrm{CC}$ offers a simple, inexpensive and agreeable tool for increasing sperm count without serious adverse effects.

\section{CONCLUSION}

Thus, it is found in this study that IUI along with ovarian hyperstimulation in males with mild to moderate oligozoospermia has better pregnancy outcome as compared to medical treatment with CC. Hence, IUI can be considered as a useful and relatively non-invasive therapeutic modality for treating infertility caused by male oligozoospermia.

\section{ACKNOWLEDGMENTS}

The completion of this research work could not have been accomplished without the effort and co-operation of Dr. Shah Alam Sheikh, Associate Professor, Department of Pathology, Silchar Medical College and Hospital.

Funding: No funding sources

Conflict of interest: None declared

Ethical approval: The study was approved by the Institutional Ethics Committee

\section{REFERENCES}

1. NICE: National Institute for Health and Clinical Excellence. Fertility assessment and treatment for people with fertility problems. NICE clinical guideline. 2013:156. Available from: https://www.nice.org.uk/guidance/cg156/evidence/fu 1l-guideline-pdf-188539453. Accessed on 21 September 2020.

2. Practice committee of the American Society for Reproductive Medicine. Diagnostic evaluation of infertile male: A committee opinion. Fertil Steril. 2015;103(3):e18-25.

3. Cohlen $\mathrm{B}$, Ombelet $\mathrm{W}$, editors. Intra-uterine insemination: evidence based guidelines for daily practice. CRC Press; 2013:11.

4. Cramer DW, Walker AM, Schiff I. Statistical methods in evaluating the outcome of infertility therapy. Fertil Steril. 1979;32:80-7.

5. Aribarg A, Sukcharoen N. Intrauterine insemination of washed spermatozoa for treatment of oligozoospermia. Int J Androl. 1995;18(1):62-6.

6. Homonnai ZT, Yavetz H, Yogev L, Rotem R, Paz GF. Clomiphene citrate treatment in oligozoospermia: comparison between two regimens of low-dose treatment. Fertil Steril. 1988;50(5):8014.

7. Kerin JF, Peek J, Warnes GM, Kirby C, Jeffrey R, Matthews $C D$, et al. Improved conception rate after intrauterine insemination of washed spermatozoa from men with poor quality semen. Lancet. 1984;323(8376):533-5.

8. Cruz RI, Kemmann E, Brandeis VT, Becker KA, Beck M, Beardsley L, et al. A prospective study of intrauterine insemination of processed sperm from men with oligoasthenospermia in superovulated women. Fertil Steril. 1986;46(4):673-7.

9. Hoing LM, Devroey P, Van Steirteghem AC. Treatment of infertility because of oligoasthenoteratospermia by transcervical intrauterine insemination of motile spermatozoa. Fertil Steril. 1986;45(3):388-91.

10. Horvath PM, Bohrer M, Shelden RM, Kemmann E. The relationship of sperm parameters to cycle fecundity in superovulated women undergoing intrauterine insemination. Fertil Steril. 1989;52(2):288-94. 
11. Martinez AR, Bernardus RE, Voorhorst FJ, Vermeiden JP, Schoemaker J. Intrauterine insemination does and clomiphene citrate does not improve fecundity in couples with infertility due to male or idiopathic factors: a prospective, randomized, controlled study. Fertil steril. 1990;53(5):847-53.

12. Confino E, Friberg J, Dudkiewicz AB, Gleicher N. Intrauterine inseminations with washed human spermatozoa. Fertil Steril. 1986;46(1):55-60.

13. Dodson WC, Whitesides DB, Hughes Jr CL, Easley III HA, Haney AF. Superovulation with intrauterine insemination in the treatment of infertility: a possible alternative to gamete intrafallopian transfer and in vitro fertilization. Fertil Steril. 1987;48(3):441-5.

14. Rashidi BH, Gharaie M, Momeni M, Tehraninejad ES. A comparison of clomiphene citrate and sequential clomiphene citrate plus human menopausal gonadotropin for use in conjunction with intrauterine insemination. Acta Medica Iranica. 2005;43(3):187-92.

15. Manganiello PD, Stern JE, Stukel TA, Crow H, Brinck-Johnsen T, Weiss JE. A comparison of clomiphene citrate and human menopausal gonadotropin for use in conjunction with intrauterine insemination. Fertil Steril. 1997;68(3):405-12.

16. Mahani IM, Afnan M. The pregnancy rates with intrauterine insemination (IUI) in superovulated cycles employing different protocols (clomiphen citrate (CC), human menopausal gonadotropin (HMG) and $\mathrm{HMG}+\mathrm{CC}$ ) and in natural ovulatory cycle. J Pak Med Assoc. 2004;54(10):503-5.

17. Chaffkin LM, Nulsen JC, Luciano AA, Metzger DA. A comparative analysis of the cycle fecundity rates associated with combined human menopausal gonadotropin (hMG) and intrauterine insemination (IUI) versus either hMG or IUI alone. Fertil Steril. 1991;55(2):252-7.

18. Sokol RZ, Steiner BS, Bustillo M, Petersen G, Swerdloff RS. A controlled comparison of the efficacy of clomiphene citrate in male infertility. Fertil Steril. 1988;49(5):865-70.

Cite this article as: Acharyya T, Choudhury AP. A comparative analysis of the cycle fecundity rates associated with ovarian hyperstimulation along with IUI versus medical management in the treatment of mild to moderate oligozoospermia in males. Int $\mathrm{J}$ Reprod Contracept Obstet Gynecol 2021;10:711-6. 